\title{
From Knowledge to Action-New Paths Towards Sustainable Consumption
}

\author{
John Thøgersen • Ulf Schrader
}

Received: 2 January 2012 / Accepted: 9 January 2012 /

Published online: 4 February 2012

(C) Springer Science+Business Media, LLC. 2012

Keywords Sustainable consumption · Policy instruments $\cdot$ Consumer behaviour

In March 2011, the Journal of Consumer Policy published a special issue on sustainable consumption. The main focus of that issue was on how the different relevant actors (consumers, business, government, and NGOs) are "putting sustainable consumption into practice" (Schrader and Thøgersen 2011). That issue continued a row of special issues on sustainable consumption (and production) in 2010 by the Journal of Industrial Ecology (in January/February, edited by Arnold Tukker, Maurie J. Cohen, Klaus Hubacek, and Oksana Mont), the Natural Resources Forum (in February, edited by David Le Blanc), the Journal of Macromarketing (June, edited by William E. Kilbourne), and the Journal of Consumer Behaviour (November/December, edited by Iain Black). The calls for these special issues were well received in the research community and so were the published articles. This, together with the ending of a number of large research projects on sustainable consumption in 2011, convinced the editors of the Journal of Consumer Policy that they should once more support the development of this fertile research field by offering space for another special issue on sustainable consumption, just 1 year after the previous one.

The backcloth of the stream of research reported in these special issues is a shared understanding that changes in consumer behaviour are crucial if we are to move to a sustainable development path. Research has shown ways through which it might be possible to fulfil consumers' needs without harming the ecological, social, and economic well-being of people today and in the future. However, the prevailing consumption patterns in modern societies are still far from being sustainable (EEA 2010). For example, the Global Footprint Network has calculated that it takes the Earth 1 year and 6 months to regenerate what we currently use in a year (Pollard et al. 2010). The imminent

\footnotetext{
J. Thøgersen $(\square)$

Aarhus School of Business, University of Aarhus, Aarhus, Denmark

e-mail: jbt@asb.dk

U. Schrader

Fachgebiet Arbeitslehre/Ökonomie und Nachhaltiger Konsum, Technische Universität Berlin, Franklinstr. 28/29, 10587 Berlin, Germany

e-mail: schrader@tu-berlin.de
} 
threats facing humanity in this connection is shared knowledge among well-informed people around the world, both in academia and in governments. As vividly expressed by the 3rd Nobel Laureate Symposium on Global Sustainability, Stockholm, Sweden, 18 May 2011, "We cannot continue on our current path. The time for procrastination is over. We cannot afford the luxury of denial. We must respond rationally, equipped with scientific evidence." (The Stockholm memorandum 2011, p. 781).

However, there is a huge gap between the available knowledge about sustainable consumption and real action towards it, at all levels of society (Thøgersen 2005). Understanding the reasons for this "knowledge-to-action gap" and developing strategies and instruments for consumer policy actors and others to close this gap is the focus of this special issue. This aim is shared with a number of research programmes in Europe and elsewhere, which have explored different ways to bridge the gap. One of these research programmes was the programme, "From Knowledge to Action-New Paths towards Sustainable Consumption" (2008-2011), within the "Social-Ecological Research" funding priority of the German Federal Ministry for Education and Research. This research programme inspired the name of this special issue and was the background for two of its articles.

A sufficient implementation of consumer rights, especially of the right to choose and the right to be informed, is a prerequisite for consumers to act responsibly in line with knowledge about sustainability (Schrader 2007). The right to choose includes the "access to a variety of products and services at competitive prices" (Kennedy 1962). This implies attractive sustainable consumption options both with regard to market offers for private households and to public infrastructure for consumers. The right to be informed, i.e., "to be given the facts he [the consumer] needs to make an informed choice" (Kennedy 1962), refers to the quantity and the quality of available information. The adequateness of facts to satisfy information needs and to transfer existing knowledge about sustainable consumption is not only a question of the right content but also of the right way to communicate it with regard to format, timing, and context.

The use of the rights to choose and to be informed is determined by their implementation and by personal factors, too. Determinants like values, attitudes, norms, or gender, education, and income are important for the subjective perception of consumer rights and responsibilities. In addition, it needs to be acknowledged that action is only of value for sustainability when positive impact can be proven. Actions considered to be sustainable at first may be "peanuts" or their positive impacts may be neutralized by rebound effects (e.g., Bilharz et al. 2008).

As illustrated in Figure 1, the articles included in this special issue each in their way contribute to our understanding of the reasons for the "knowledge-to-action gap" and to the development of strategies and instruments to close this gap and promote sustainable consumption.

In their article, "Endorsing sustainable food consumption: Prospects from public catering," Wahlen et al. (2012) show how a change in the often neglected public infrastructure can happen and improve the conditions for sustainable consumption. Building on Dean's (2010) conceptualization of a regime of practices with its four dimensions (rationalities, technologies, visibilities, and identities), they apply qualitative research methods to analyse policy makers', catering professionals', and consumers' views on the introduction of sustainable public catering in Finland. The authors emphasize that, in order to realize a supply structure that promotes sustainable consumption, more attention need to be paid to the role of practitioners and their interpretation of sustainable practices.

A number of new products and services for private households, which allow or facilitate more sustainability in energy consumption, have become prominent under the broad term "smart homes." In their article "Smart Homes as a means to sustainable energy 


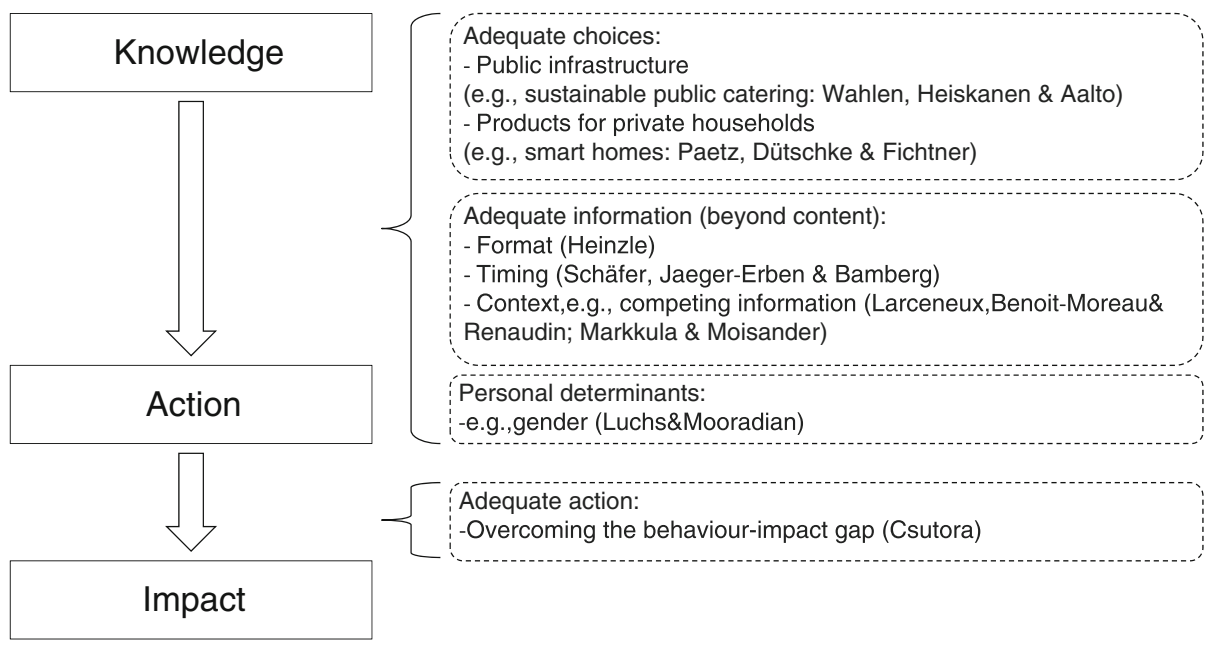

Fig. 1 Topics covered in this special issue

consumption," Paetz et al. (2012) analyse consumer perceptions regarding and responses to these offers (including variable electricity tariffs, smart metering, smart appliances, and home automation), collected by means of focus group interviews in a fully equipped smart home. According to this study, the most important advantage of smart home technologies for consumers is the possible cost reduction; the most important impediments are a possible lack of flexibility and control and privacy concerns. These aspects have to be considered to allow further diffusion of smart home technologies.

Smart homes are a good example of how closely (new) choice options and information are often connected. For example, smart meters will only lead to electricity saving if consumers are willing and able to use the additional information generated by this new technology and change behaviour accordingly. Similarly, eco-labels, as instruments of consumer information, are only effective if more sustainable products exist that deserve to be rewarded. This is only one among a wide range of contingencies for consumer information to reach its intended effects, however.

In her paper, "Disclosure of energy operating cost information: A silver bullet for overcoming the energy efficiency gap?" Heinzle (2012) shows that the format of information provided by an energy efficiency label is important for its effect. A choice-based conjoint experiment reveals that consumers are willing to pay more for an energy-efficient TV set when its energy consumption is communicated in watts rather than in annual energy costs. However, according to her study, the most effective way to communicate the possible energy savings is to put the expected lifetime energy costs on the label.

Based on their study of "Life events as windows of opportunity for changing towards sustainable consumption patterns," Schäfer et al. (2012) find that also the timing of information is important for its effects. Life events like the birth of a first child or moving into a new town necessarily bring about new consumption patterns and a change of old habits. Thus, the authors experimentally stimulated a change towards more sustainable consumption habits soon after such live events. However, unexpectedly, they found that participants some weeks after they had gone through the studied live events were less likely to react to informational interventions (more or less individualized consumer information and consultancy) than participants in stable life situations. 
Qualitative interviews revealed that the lack of intervention effects might be due to important changes having happened before the intervention. For example, the change of nutrition habits in connection with childbirth already starts during pregnancy, which may limit the willingness to change more or differently a few weeks after birth, when the intervention was implemented. Thus, it is crucial (but difficult) to time the intervention correctly in connection with a life event.

The effectiveness of information also depends on many aspects of its context. In their paper, "Why might organic labels fail to promote sustainable consumption?" Larceneux et al. (2012) investigate the influence of brand equity on labelling outcomes. Their experimental study revealed a positive effect of eco-labels on consumers' product quality assessment, but the positive effect is significantly stronger for low-equity than for high-equity brands. Thus, they recommend that consumer policy should promote especially the use of eco-labelling on lower-equity brands to foster more sustainable consumer action.

Markkula and Moisander (2012) deal with the importance of information context in a broader sense. In their article, "Consumers and discursive confusion over sustainable development," they discuss the heterogeneous and sometimes contradictory information consumers get with regard to consumption and sustainability issues. Based on qualitative interviews on fashion consumption, they uncover the discursive polyphony consumers often have to face. They show that, in practice, individual consumer responsibility for negative social and ecological process and product characteristics of the clothing they buy is drowned in discourses on financial responsibility, political responsibility, and aesthetical norms. This situation creates discursive confusion for many consumers and inactivity with regard to sustainable consumption. Thus, the authors argue that one reason for the "knowledge-to-action gap" is that uncontested knowledge often does not exist, which leads to a lack of clear action alternatives. Consumer policy should take this more into account when promoting sustainable consumption and become better at dealing with the discursive polyphony in this area.

Available information and the subjective perception of existing choice options vary depending on various personal characteristics, including gender. Accordingly, Luchs and Mooradian (2012) elucidate the much debated gender differences in sustainable consumption in their paper "Sex, personality and sustainable consumer behaviour." Using insights from personality psychology, they take a closer look at the common observation that women are usually more prone to environmental friendly and socially responsible behaviour than men. Their experimental study reveals that gender differences in personality, especially agreeableness, explain gender differences in sustainable consumer behaviour. Thus, they recommend that consumer policy to promote sustainable action should focus on relevant personality traits rather than specifically on women since also men can have the relevant personality trait.

Last, but not least, Csutora (2012) addresses "The behaviour-impact-gap problem." Her survey and measurements show that Hungarian consumers with above-average self-reported pro-environmental behaviour ("green" consumers) do not have a significantly smaller environmental footprint than those who do not voluntarily engage in more environmental friendly consumer behaviour ("brown" consumers). Among other things, this finding sheds light on the huge challenge it is to define and measure real pro-environmental behaviour, $i$. e., in terms of its impacts (Stern 2000). For consumer policy, it highlights the necessity of informing and educating consumers about activities with the highest environmental impact (Gardner and Stern 2008). As emphasized by Csutora, it also suggests that the environmental impact of promoting voluntary behaviour change is limited and that governments need to focus much more on making contextual changes that favour the environment.

Except for the shared goal of understanding and possibly narrowing the "knowledgeaction-impact gaps," these contributions differ in methodological approaches and many 
other important ways. However, they all contribute to increasing our shared knowledge on these gaps and on how to develop consumer policies that will successfully narrow the gaps and foster consumption with a positive impact on sustainability. It is the motto of some activists that what we need now is not more knowledge but more action for sustainable consumption. Unfortunately, this is not completely true. The contributions collected in this special issue demonstrate that we need more action and we need more knowledge for the initiation, diffusion, and improvement of the right actions. Hence, this special issue of the Journal of Consumer Policy is definitely not the last to be written on this topic.

Acknowledgements The special issue editors are grateful to the competent input from 38 anonymous reviewers. Without their help and expertise this special issue would not have been possible.

\section{References}

Bilharz, M., Lorek, S., \& Schmitt, K. (2008). Key points of sustainable consumption: Focusing sustainability communication on aspects which matter AND appeal. In T. G. Ken, A. Tukker, C. Vezzoli, \& F. Ceschin (Eds.), Sustainable consumption and production: Framework for Action, Proceedings: Refereed Sessions $I-I I$ (pp. 287-307). Brussels: SCORE.

Csutora, M. (2012). One more awareness gap? The behaviour-impact-gap problem. Journal of Consumer Policy. doi:10.1007/s10603-012-9187-8

Dean, M. (2010). Governmentality - Power and rule in modern society (2nd ed.). London: Sage.

European Environment Agency (EEA). (2010). The European environment-State and outlook 2010. Copenhagen: European Environment Agency.

Gardner, G. T., \& Stern, P. C. (2008). The short list. The most effective actions U.S. households can take to curb climate change. Environment, 50(5), 12-24.

Heinzle, S. L. (2012). Disclosure of energy operating cost information: A silver bullet for overcoming the energy efficiency gap? Journal of Consumer Policy. doi:10.1007/s10603-012-9189-6

Kennedy, J. F. (1962). Special message to the Congress on protecting the consumer interest. March 15, 1962. Washington, DC.

Larceneux, F., Benoit-Moreau, F., \& Renaudin, V. (2012). Why might organic labels fail to promote sustainable consumption? Marginal labelling and brand equity effects. Journal of Consumer Policy. doi:10.1007/s10603-011-9186-1

Luchs, M. G., \& Mooradian, T. A. (2012). Sex, personality and sustainable consumer behaviour: Elucidating the gender effect. Journal of Consumer Policy. doi:10.1007/s10603-011-9179-0.

Markkula, A., \& Moisander, J. K. (2012). Consumers and discursive confusion over sustainable development. Journal of Consumer Policy. doi:10.1007/s10603-011-9184-3.

Paetz, A.-G., Dütschke, E., \& Fichtner, W. (2012). Smart Homes as a means to sustainable energy consumption: A study on consumer perceptions. Journal of Consumer Policy. doi:10.1007/s10603-011-9177-2.

Pollard, D., Almond, R., Duncan, E., Grooten, M., Hadeed, L., Jeffries, B., et al. (2010). The living planet report 2010. WWF International, Zoological Society of London and Global Footprint Network.

Schäfer, M. B., Jaeger-Erben, M., \& Bamberg, S. (2012). Life events as windows of opportunity for changing towards sustainable consumption patterns? Results from an intervention study. Journal of Consumer Policy. doi:10.1007/s10603-011-9181-6.

Schrader, U. (2007). The moral responsibility of consumers as citizens. International Journal of Innovation and Sustainable Development, 2, 79-96.

Schrader, U., \& Thøgersen, J. (2011). Putting sustainable consumption into practice. Editorial. Journal of Consumer Policy, 34, 3-8.

Stern, P. C. (2000). Towards a coherent theory of environmentally significant behavior. Journal of Social Issues, 56, 407-424.

The Stockholm memorandum. (2011). AMBIO: A Journal of the Human Environment, 40, 781-785.

Thøgersen, J. (2005). How may consumer policy empower consumers for sustainable lifestyles. Journal of Consumer Policy, 18, 143-178.

Wahlen, S., Heiskanen, E., \& Aalto, K. (2012). Endorsing sustainable food consumption: Prospects from public catering. Journal of Consumer Policy. doi:10.1007/s10603-011-9183-4. 